\title{
ANÁLISE BIBLIOGRÁFICA: PROTEÍNA PRÍON E ENCEFALOPATIAS TRANSMISSÍVEIS
}

\author{
* Ruri Miranda Machado I \\ Andreina da Silva Miranda II \\ Bruna Braga Dantas
}

\begin{abstract}
RESUMO
As doenças priônicas são enfermidades neurodegenerativas raras que causam diversos sintomas neuropsiquiátricos, devido ao acúmulo de príons, pequenas partículas resistentes a inativação, formadas por genes, que se modificam originando proteínas mutantes. Assim sendo, o presente artigo tem por objetivo a análise literária de publicações sobre a proteína príon e suas encefalopatias transmissíveis. Trata-se de um levantamento bibliográfico, de caráter histórico, cuja coleta foi efetuada entre os anos de 2018 a 2019, composta por artigos obtidos a partir de plataformas de pesquisas como o Google Acadêmico, PubMed e Scielo. Para complementação do estudo, foram também utilizados dados obtidos do Portal do Ministério da Saúde. Posteriormente, foi realizada uma análise a partir da leitura criteriosa dos artigos e utilizou-se como parâmetros de inclusão: ser publicado em inglês ou português. Foram excluídos estudos em que não se tinha acesso completo, monografias, trabalhos de conclusão de curso que envolvessem somente animais. Através deste estudo, constatou-se que nos últimos 15 anos foram notificados uma média de 3,74 casos de óbitos por encefalopatias espongiformes no Brasil, sendo o estado de São Paulo o mais acometido. Quanto ao cenário mundial, foram notificados 177 casos no Reino Unido e 27 na França. Portanto, é de grande justificabilidade a continuação de pesquisas/estudos nesta área, visto que os príons causam encefalopatias e isso foi visto em vários países, inclusive no Brasil.
\end{abstract}

PALAVRAS-CHAVE: Encefalopatias Espongiformes. Doenças Neurodegenerativas. Príons. Sistema Nervoso.

Acadêmica do curso de Fisioterapia. Faculdade de Enfermagem Nova Esperança - FACENE. CEP: 58065-033, João Pessoa, Paraíba, Brasil. *Autor correspondente: ruryifba@outlook.com Orcid: 0000-0002-3997-9557 Acadêmica do curso de Odontologia. Faculdade de Enfermagem Nova Esperança - FACENE. CEP: 58065-033, João Pessoa, Paraíba, Brasil. Orcid: 0000-0002-0630-8933 Enfermeira, Doutora em Biotecnologia. Universidade Federal de Campina Grande - UFCG, Unidade III Acadêmica de Saúde. CEP: 58175-000, Cuité, Paraíba, Brasil; Orcid: 0000-0001-8807-1601 


\section{INTRODUÇÃO}

As doenças priônicas acometem o Sistema Nervoso (SN), por isso, para compreendê-las, é importante ter uma visão completa do organismo que, a partir de um núcleo central, distribui por todo o corpo ramificações da complexa estrutura nervosa. ${ }^{1}$ A estrutura óssea do crânio não contém apenas o cérebro, mas algo maior, o encéfalo, do qual o cérebro é parte integrante. Além do cérebro, fazem parte do encéfalo o cerebelo e o tronco cerebral. O primeiro exerce importante papel na homeostasia e controla as atividades dos diversos grupos musculares; o tronco cerebral une todas as partes do encéfalo à medula espinhal. ${ }^{1,2}$

Conforme abordado pela revista, Joint Programme - Neurodegenerative Disease Research - JPND, ${ }^{2}$ os neurônios são a unidade funcional do sistema nervoso, não se reproduzem nem podem ser substituídos e, desta forma, quando sofrem lesões ou morrem não se regeneram. Sendo assim, patologias no sistema nervoso podem resultar em doenças incuráveis e debilitantes que têm como consequência a degeneração progressiva e/ ou morte dos neurônios, causando problemas no movimento (ataxias), ou na função mental (demências).

As demências são as responsáveis pela maior carga das doenças associadas ao SN, como o Alzheimer, a doença de Parkinson (DP), o kuru, a Síndrome de Gerstmann-StrausslerScheinker (SSG), doença de Creutzfeldt-Jacob (CJD) e insônia familiar fatal, das quais as quatro últimas são provocadas por Prions ( $\operatorname{PrP}$ ), agentes proteicos infecciosos com capacidade de propagação em hospedeiros suscetíveis sem o auxílio de ácido nucléico. ${ }^{3}$

Doenças priônicas são enfermidades neurodegenerativas raras que causam diversos sintomas neuropsiquiátricos, devido ao acúmulo de pequenos agentes infecciosos compostos unicamente por proteínas príons, que levam a apoptose e morte celular no tecido nervoso. São doenças pertencentes a Síndrome de Demência Rapidamente Progressiva (DRP), que podem evoluir de modo subagudo em período menor que um ano e são resistentes as proteases, enzimas do corpo que normalmente podem degradar as proteínas mal enoveladas ou danificadas. , $^{3,4}$

Conforme ressalta Rovirosa, ${ }^{5}$ os príons são pequenas partículas, resistentes a inativação, formadas por genes que modificam proteínas normais. É uma proteína composta de 253 aminoácidos, com caráter patogênico derivado de diferentes configurações espaciais. A proteína em sua forma celular ( $\operatorname{PrPC}$ ) possui uma dobra baseada em hélices alfa que é sensível à proteólise completa, ao invés do príon que se configura parcialmente resistente a proteólise.

Há muitas pesquisas com a finalidade de descobrir o mecanismo de ação dos príons, bem como as diversas patologias causadas por eles. Desta forma, o presente artigo tem por objetivo a análise literária de publicações sobre proteína príon e encefalopatias espongiformes que acometem humanos.

\section{MATERIAL E MÉTODOS}

O presente estudo consiste em um levantamento bibliográfico de série histórica, com a seleção de artigos desde o primeiro relato, publicado em 1922, até publicações 
mais recentes do ano de 2019, estabelecendo assim a contextualização histórica da relação da proteína príon e encefalopatias espongiformes.

A coleta de dados foi realizada entre os anos de 2018 a 2019, sendo composta por artigos obtidos a partir de plataformas de pesquisas que muito contribuíram para o embasamento teórico desse trabalho, como o Goolge Acadêmico, PubMed e Scielo utilizando os Operadores Booleanos: AND e OR, como norteadores para combinar os termos da pesquisa.

Após a busca nas bases de dados, a análise foi realizada a partir da leitura criteriosa dos artigos. Estes, foram sequencialmente organizados em uma tabela de revisão, contendo os seguintes tópicos: título do

\section{RESULTADOS E DISCUSSÃO}

\section{Contexto histórico dos príons}

A primeira aparição histórica das doenças priônicas ocorreu há 200 anos. Descrita por McGowan, com o reconhecimento em ovelhas, de uma doença neurológica de evolução fatal, a zoonose conhecida pelos pecuaristas como scrapie. Os animais comprometidos por esta doença apresentam excitabilidade, coceira, ataxia e paralisia, morrendo em pouco tempo. Somente em 1954, Sigurdsson propôs o termo "infecção lenta" após estudar quadros dessa moléstia em animais, sendo inicialmente caracterizadas por um longo período de latência (meses a anos), por serem geralmente fatais e se limitarem a uma espécie de animal e de um órgão ou sistema comprometido. ${ }^{6,7}$

Os depósitos amiloides do Scrapie impulsaram Prusiner e Cols a realizarem seu isolamento e purificação, a fim de reproduzir a doença em outros animais apenas com essa artigo, autor, objetivos e ano de publicação. Utilizaram-se descritores como: "Prions and nervous system", "Prions and pathogens", com o objetivo de construir um contexto histórico. Como parâmetros de inclusão aplicou-se: ser publicado em inglês ou português. Foram excluídos estudos em que não se tinha acesso completo, monografias, trabalhos de conclusão de curso e estudos que envolvessem somente animais.

Dessa forma, foram analisados 30 estudos, sendo 21 utilizados, os quais foram selecionados minuciosamente pelo ano de publicação, tema ou relevância da pesquisa. Para complementação do estudo, utilizaram-se também dados obtidos do Portal do Ministério da Saúde. proteína. O sucesso experimental permitiuIhes identificar este agente como proteína infecciosa ou príon. ${ }^{5}$

Em 1970, J.S. Griffith e R. Latarget propuseram que os príons podem ser tratados de erros no processamento de proteínas, causando o depósito de peptídeos anormais e se opuseram a etiologia viral, dada a já conhecida falta de DNA e RNA. Mostraram ainda, que os príons estavam associados a um longo período de incubação, a falta de resposta de infiltrado imunológico e inflamatório de estruturas visíveis sob o microscópio eletrônico e sua extrema resistência a radiação ultravioleta, raios $X$ e ao mesmo tempo, a sua sensibilidade a métodos que degradam proteínas. ${ }^{8}$

Dessa forma, a proteína priônica passou a ser designada como $\operatorname{PrP}$ e, com o suceder das pesquisas, foi esclarecido que os quadros patológicos podem ser de natureza 
infecciosa, genética ou sem nenhum padrão de transmissão reconhecível, denominada esporádica. ${ }^{6}$ Esta proteína é codificada por um gene presente em todas as células nucleares em humanos e em outros mamíferos, mas é expresso em maior magnitude em membranas plasmáticas de neurônios, especialmente em sinapses e junções neuromusculares. Por serem proteínas estruturais dos organismos, existindo em baixas concentrações nos sistemas biológicos, proteínas do tipo príon quando a conformação PrPSC (forma alterada estruturalmente da PrPC) são associadas as doenças neurodegenerativas de prognóstico delicado e progressivo., ${ }^{9,11}$

Com o advento da tecnologia e através da engenharia genética, foi possível realizar a caracterização da estrutura ultrassecundária da molécula priônica, isolada em fluido cortical, subcortical e no líquido cefalorraquidiano (LCR) de pacientes com demência progressiva rápida e que microscopicamente estavam relacionados com a degeneração espongiforme do tecido cerebral. Esta organização molecular possuía múltiplas folhas betas dobradas com grandes capacidades de replicação. ${ }^{9}$

Como já ressaltado, as encefalopatias espongiformes são condições neurodegenerativas fatais raras. E conforme Jerusa, ${ }^{10}$ possuem uma estimativa a incidência anual de aproximadamente um por milhão de indivíduos e apresenta mutações que levam a quatro principais fenótipos: doença Creutzfeldt-Jakob, Kuru, doença de Gerstmann-Sträussler-Scheinker (GSS) e insônia fatal familiar.

\section{CONFIGURAÇÃO EPIDEMIOLÓGICA DAS DOENÇAS PRIÔNICAS}

Conforme apresentado por Costa, ${ }^{11}$ os Príons são proteínas periféricas codificadas por genes que ocorrem em vertebrados, sendo este gene ativo no cérebro e em outros tecidos do sistema nervoso central onde se encontram ligadas à superfície dos neurônios. Por serem proteínas estruturais dos organismos, existindo em baixas concentrações nos sistemas biológicos, proteínas do tipo príon quando a conformação PrPSC (forma alterada estruturalmente da PrPC) são associadas as doenças neurodegenerativas de prognóstico delicado e progressivo.

De acordo com Neves, ${ }^{12}$ a partir de 1974 , Prusiner começou seu trabalho laboratorial, no sentido de esclarecer o agente etiológico causador das doenças neurodegenerativas (encefalopatias). Com isso, concluiu que o agente não continha ácido nucléico e parecia tratar-se principalmente, ou até mesmo exclusivamente, de proteína. Posteriormente, Prusiner postulou que a proteína priônica pode existir em duas conformações distintas, que seu processo patológico está ligado a mudanças nas estruturas secundária e terciária do PrP e os quadros podem ser de natureza infecciosa, genética ou esporádica.

Sabe-se que a estrutura da forma celular PrPC (proteína na conformação normal, não patogênica) é constituída basicamente por $a$-hélices enquanto PrPSc (forma scrapie) possui alto conteúdo de folhas- $\beta$. A conversão de PrPC em PrPSc favorece a agregação da proteína e a formação de fibras amiloides. ${ }^{3}$

Os príons estão envolvidos na patogênese de diferentes doenças, levando à morte de muitas pessoas, como retrata a Figura 1, que apresenta o Brasil e os Estados com maior incidência de óbitos ocorridos por encefalopatias. A região Norte não apresentou registros de casos, enquanto o Sudeste é o maior afetado, sendo que o estado de São Paulo apresentou mais de 50 óbitos entre 20052010. Seguido de Rio de Janeiro com 13 a 15 e 


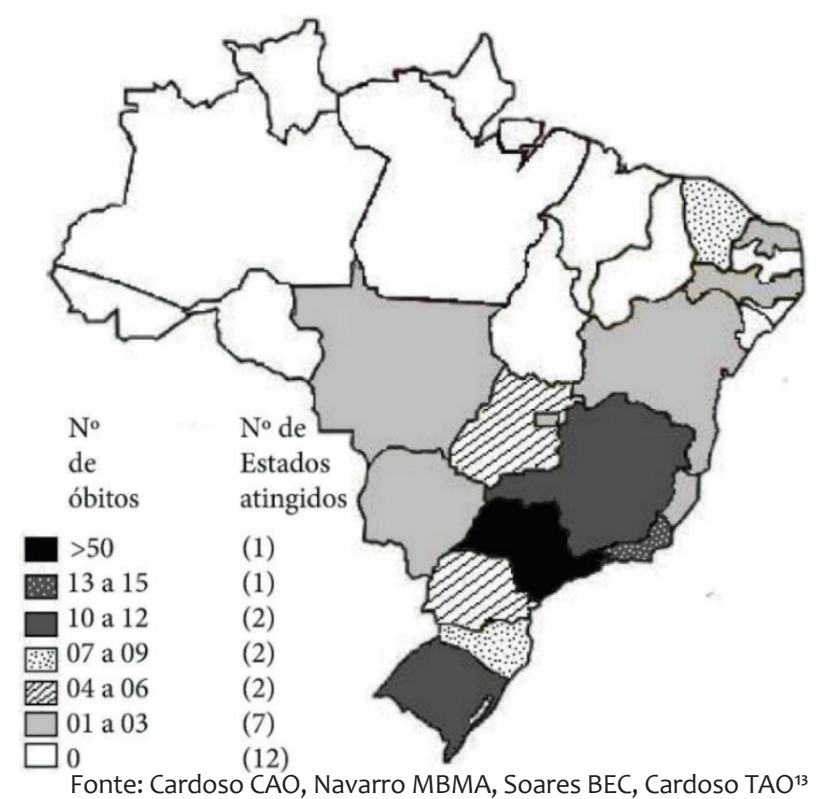

FIGURA 1: Distribuição espacial dos óbitos por encefalopatias transmissíveis pelos estados brasileiros, no período 2005-2010.

Minas Gerais com 10 a 12 casos de óbitos. ${ }^{13}$

Em cenário mundial, essas doenças também causam uma grande repercussão, como evidenciado na Figura 2, chamando atenção para dois países, os quais apresentaram os maiores registros. Sendo eles, o Reino Unido e a França com 177 e 27 casos notificados, respectivamente. ${ }^{13}$



FIGURA 2: Cenário mundial de casos notificados das doenças espongiformes transmissíveis

Dentre as diversas encefalopatias, o scrapie acomete especificamente cabras e ovelhas. No entanto, outras doenças semelhantes, como, o kuru, doença de Creutzfeldt-Jacob (DCJ), síndrome de Gerstmann-Straussler-Scheinker (SSG) e insônia familiar fatal, atingem estritamente os seres humanos. Tais patologias apresentam particularidades como: tempo de início (anos), incubação e duração após manifestação, as quais são exemplificadas abaixo na Tabela 1. ${ }^{14,16,7,18,20,21}$ 
TABELA 1: Características da progressão das encefalopatias transmissíveis que acometem humanos

\begin{tabular}{|c|c|c|c|}
\hline & Tempo de Início (Anos) & Tempo de Incubação & Duração após Manifestação \\
\hline KURU & 40 anos & Indeterminado & 3 a 6 meses \\
\hline CREUTZFELDT-JACOB (DCJ) & $60-69$ anos & $\begin{array}{c}\text { Período variável, podendo ser } \\
\text { de anos ou décadas }\end{array}$ & 1 ano \\
\hline $\begin{array}{l}\text { GERSTMANN-STRAUSSLER- } \\
\text { SCHEINKER (SSG) }\end{array}$ & $43-48$ anos & $\begin{array}{c}\text { Período variável, podendo ser } \\
\text { de anos ou décadas }\end{array}$ & 5 ano \\
\hline INSÔNIA FAMILIAR FATAL & 56 anos & $\begin{array}{c}\text { Período variável, podendo ser } \\
\text { de anos ou décadas }\end{array}$ & 13 meses \\
\hline
\end{tabular}

\section{Kuru}

Edgard, Gajdusek e Zigas ${ }^{7}$ descreveram em 1957 uma doença peculiar denominada "kuru" que afetava crianças e adultos, especialmente do gênero feminino em Eastern Highlands, uma província do planalto de Papua Nova Guiné.

O Kuru foi descrito como a causa mais comum de morte entre as mulheres desta população, devido ao ritual de canibalismo, no qual o cérebro e outros órgãos eram destinados a elas, enquanto os homens ingeriam os músculos dos cadáveres. Os nativos denominaram a doença de Kuru devido aos tremores característicos da doença. ${ }^{13}$

Hadlow notou similaridades, em 1959, entre o kuru e uma doença endêmica há séculos no Reino Unido e ainda pouco conhecida, descrita pela primeira vez há 227 anos, o scrapie. No mesmo ano, outros pesquisadores também relataram similaridade entre o kuru e a DCJ. Contudo, somente após 30 anos, com os experimentos de Chandler, foi possível transmitir o scrapie para ratos e o termo encefalopatia espongiforme subaguda passou a ser utilizado. ${ }^{14}$

Posteriormente em 1966, Gajduseck para tentar demonstrar que o Kuru endêmico entre os habitantes da Papua-Nova Guiné era transmissível, realizou um ensaio experimental inocularam macerado cerebral de pacientes mortos por Kuru no cérebro de primatas que, após vários meses, desenvolveram as doenças. Baseado na mesma premissa, Gibbs $^{5}$ relatou, em 1969, a transmissão bem sucedida de DCJ para chimpanzé. A partir de então, foi introduzido o termo transmissível às encefalopatias espongiformes, o qual é empregado atualmente às doenças priônicas. ${ }^{7}$

Embora, por motivos epidemiológicos, a etiologia do kuru tenha sido considerada infecciosa, os pacientes não apresentavam sinais ou sintomas meningoencefálicos (febre, confusão, convulsões ou coma), nenhuma pleocitose do fluido cefalorraquidiano ou nível elevado de proteína e, na autópsia, não há sinais de patologia cerebral inflamatória. ${ }^{15}$

O Kuru teve sua origem em rituais canibalísticos atingindo principalmente mulheres e crianças que adoeciam, ao entrarem em contato direto, por ingestão, ou por meio de cortes e queimaduras, com tecido nervoso de cadáveres contaminados. Os primeiros sinais clínicos da doença são movimentos involuntários e tremores, dificuldade para falar e engolir, instabilidade emocional, além de demência moderada. $E$ nas fases mais avançadas, o doente apresentava-se mudo, flácido e bastante debilitado. ${ }^{16}$ 
O aspecto histológico e patológico da doença consiste na presença de alterações espongiformes e deposição de placas amiloides, principalmente no cerebelo, parte anterior da medula espinhal, olivas inferiores e do tálamo. ${ }^{7}$

A cessação das práticas de canibalismo na década de 1950 encerrou casos incidentes de kuru. No entanto, 11 novos casos foram identificados entre julho de 1996 e junho de

\section{Creutzfeldt-Jacob (DCJ)}

A DCJ é a encefalopatia que mais acomete os seres humanos no mundo, sendo de origem idiopática e de formas hereditárias. Com uma incidência anual de 0,5 casos por milhão de pessoas, apresenta-se como uma doença neurológica fatal, degenerativa e com longo período de incubação. A variante da doença, que parece estar relacionada ao agente da EEB; e a casos iatrogênicos transmitidos a partir de enxertos de dura-máter, transplantes de córnea e procedimentos neurocirúrgicos. ${ }^{3}$

Tem início mais comumente entre 55 e 70 anos de idade, com um maior número de casos entre 60 e 69 anos. Em um terço dos casos manifesta-se como ataxia de marcha, afasia ou perda visual. ${ }^{7}$ A progressão da doença é inexorável e a demência notável, o mais característico e constante sinal é a mioclonia, a contração muscular súbita e involuntária frequentemente provocada por estímulos
2004, com um período de incubação provável de mais de 50 anos em alguns. ${ }^{17}$ Cabe ressaltar, que Edgard $^{7}$ constatou que crianças órfãs nascidas de mães portadoras desta patologia, não apresentaram a doença até hoje. Fato que evidencia que as crianças das tribos afetadas não foram infectadas através da placenta ou do leite materno de suas mães.

sensoriais variados. Em estágios tardios, o paciente encontra-se afásico, demenciado e a mioclonia pode desaparecer, como também os distúrbios visuais e sinais cerebelares, incoordenação e dificuldade de marcha se tornam menos comuns. ${ }^{18}$

Embora vários mecanismos hipotéticos para sua origem e propagação tenham sido propostos, incluindo a exposição à carne de gado infectada, as teorias mais aceitas são: a transmissão iatrogênica, minoria atualmente, e as mutações somáticas espontâneas (constituindo a DCJ familiar), sendo herdada com padrão autossômico dominante com mutações definidas no gene produtor da proteína (PrPC). No entanto, Tyler ${ }^{19}$ afirmou que a maioria dos casos são esporádicos e não mostram relação direta com mutações específicas.

\section{Síndrome de Gerstmann-Straussler-Scheinker (SSG) e Insônia Familiar Fatal}

Tanto a Síndrome de Gerstmann Straussler Scheinker (SSG), quanto a Insônia Familiar Fatal são casos de encefalopatias espongiformes de caráter hereditário, mas que podem ser transmissíveis em casos de cirurgias feitas com material contaminado pela isoforma infectante, transplante sanguíneo ou de órgãos, que demonstram uma unicidade deste agente no processo saúde doença. ${ }^{20,21}$

Assim como na doença de CreutzfeldtJakob, o local de mutação do gene PrP determina diretamente a patologia a ser desenvolvida. Se a prolina no local 102 for substituída por uma leucina, ou se a alanina no 
local 117 for trocada por uma valina, ocorrerá a doença de SSG. Se a mutação levar a uma troca do aminoácido na posição 129 de valina para metionina desenvolverá a encefalopatia conhecida como Insônia Familiar Fatal.?

A doença de Gerstmann Straussler Scheinker é muito rara, autossômica dominante com uma incidência de 1-10 casos por 100 milhões de pessoas, por ano. A marca do curso clínico desta doença é a degeneração do cerebelo, acompanhada por graus variáveis de demência em indivíduos com idade entre 43-48 anos, apesar de terem sido descritos sintomas em doentes mais velhos. Sabe-se ainda que a variante da SSG dura cerca de 5 anos, antes de culminar com a morte, e os sintomas incluem incoordenação, ataxia da marcha, hiporreflexia e fraqueza dos membros inferiores. As mioclonias não estão presentes e o grau demencial varia entre as famílias afetadas. ${ }^{20}$

Por outro lado, a Insônia Familiar Fatal, como ressaltado anteriormente, é de origem hereditária e caracteriza-se por uma mutação no local do gene PrP, propiciando Síndrome

\section{CONSIDERAÇÕES FINAIS}

É notório, que os príons
estão associados a vários distúrbios neurodegenerativos infecciosos, como o kuru, a doença de Creutzfeldt-Jakob, a Síndrome de Gerstmann-Straussler e a Insônia Familiar Fatal, que atacam os seres humanos. Tratase de uma proteína atípica, ou seja, fora de sua conformação normal cujas patologias por ela acometidas podem ou não apresentarem etologias conhecidas, porém é comum o fato de não terem cura.

A partir da análise dos artigos, contatou-se que nos últimos 15 anos foram notificados uma média de 3,74 casos de óbitos por encefalopatias espongiformes no Brasil. Porém, nesse mesmo período, tiveram regiões de Insônia, disautonomia, e défices motores. É uma doença rapidamente fatal com uma média de 13 meses a contar desde o início dos sintomas até a morte. Tem início na meia-idade, com uma média de 56 anos. Os portadores desta Síndrome desenvolvem insônia progressiva com a perda do padrão circadiano normal do sono, provocando alterações em seus estados mentais e comportamentais incluindo déficit de atenção, dificuldades de concentração e memória, culminando em alucinações, com manifestações demenciais raras. ${ }^{21}$

À medida que a doença progride, ocorrem alterações da atividade motora como ataxia, mioclonia e espasticidade. Trata-se da única doença priônica a causar disautonomia e alterações endócrinas. A disautonomia pode induzir hiperhidrose, hipertermia, taquicardia e hipertensão e as alterações endócrinas manifestam-se com uma diminuição na secreção de hormônio adrenocorticotrófico (ACTH), aumento da secreção de cortisol e perda da variação normal diurna nos níveis de somatropina $(\mathrm{GH})$, melatonina e prolactina. ${ }^{7}$

em que não ocorreu nenhum óbito como na região Norte e tiveram regiões que foram registrados uma alta taxa de mortalidade como no Sudeste. No que se refere ao cenário mundial, essas doenças também causam grande repercussão, se destacando o Reino Unido com 177 casos e a França com 27 casos, sendo estes os maiores registros notificados.

Cabe ressaltar, que são poucos os estudos encontrados com relação aos príons e suas encefalopatias espongiformes, mesmo que em um vasto espaço temporal onde só foram encontrados 21 artigos para compor o estudo, sendo ainda pertinente a necessidade de muitas pesquisas acerca do tema. Visto que, possibilitam o aprofundamento do 
conhecimento destas patogenias, para caracterizar os príons e sua maneira de acarretar doenças. É de grande pertinência então a continuação de pesquisas nesta área possibilitando assim, possíveis tratamentos que propiciem a cura dessas doenças, por meio de drogas que sejam capazes de impedir que genes do tipo PrP patogênico transformem a proteína normal em infectante.
Portanto, tendo em vista que ainda não há cura para as doenças causadas por príons, o fundamental é preveni-las. Sendo o processo de esterilização de instrumentos cirúrgicos e hospitalares em geral, significativo para minimizar os riscos de contaminação se forem capazes de destruir os príons e não apenas outros microrganismos.

\title{
BIBLIOGRAPHIC ANALYSIS OF PROTEIN PRION AND ITS TRANSMISSIBLE ENCEPHALOPATHIES
}

\begin{abstract}
Prion diseases are rare neurodegenerative diseases that cause various neuropsychiatric symptoms due to the accumulation of prions, small particles resistant to inactivation formed by genes that modify causing mutant proteins. Thus, this article aims at the literary analysis of publications on the prion protein and its transmissible encephalopathies. This is a bibliographic review of historical character, and the collection was carried out between 2018 and 2019, the articles were obtained from research platforms such as Google Scholar, PubMed and Scielo, to complement the study, data obtained from the Ministry of Health website were also used. Subsequently, an analysis was performed from the careful reading of the articles and the following inclusion parameters were used: to be published in English or Portuguese. Studies in which there were no full access, theses, completion of course papers and involving only animals were excluded. Through this study it was verified that in the last 15 years an average of 3.74 cases of spongiform encephalopathies Brazil, being the state of São Paulo the most affected. Regarding the world scenario, 177 cases were reported in the United Kingdom and 27 in France. Therefore, it is highly justifiable to continue research / studies in this area, since prions cause encephalopathies and this has been seen in several countries, including Brazil.
\end{abstract}

KEYWORDS: Spongiform encephalopathies. Neurodegenerative Diseases. Prions. Nervous System.

\section{REFERÊNCIAS}

1. Johnson RT. Viral infections of the nervous system. Lippincott-Raven. 2. ed. Philadelphia; 1998.

2. Joint Programme Neurodegenerative Disease Research (JPND). [Cited 2018 Sept 20] Available from: http://www.neurodegenerationresearch. eu/pt-pt/sobre-a-jpnd/.

3. Pinto AFC, Freitas RB, Coelho FA, Soares CQG, Fidélis CF, Fófano GA, et al. Creutzfeldt-Jakob disease: notified and confirmed cases in the state 
of Minas Gerais from 2007 to 2016. Rev. Científica Fagoc. 2018; 2(2); 35-42.

4. Takada, L. T., Kim, M. O., Cleveland, R. W., Wong, K., Forner, S. A., Gala, I. I., ... \& Geschwind, M. D. Genetic prion disease: experience of a rapidly progressive dementia center in the United States and a review of the literature. Am. J. Med. Genet. B Neuropsychiatr. Genet. Part B: Neuropsychiatric Genetics. 2017; 174 (1): 36-69.

5. Rovirosa LC. Prion induced spongiform encephalopathy of Creutzfeldt-Jakob disease. RevMed Chile. 2019; 147:1176-83.

6. McGowan JP. Scrapie in sheep. Scott J Agric. 1922; (5): 365-75.

7. Edgard G. Caracterização de um receptor para o príon através da teoria da hidropaticidade complementar dos aminoácidos. Evidencias da interação príon-laminina. [Tese]. Piracicaba: Faculdade de Odontologia, Universidade Estadual de Campinas, São Paulo; 1996.

8. González GT, Zuleta UES, Grosso LAG. Prion Theory - Prion Diseases. Acta. Neurol. Colomb. 2015; 31(1): 101-12.

9. Alemán-Iñiguez JM, Alemán-Iñiguez PJ, Guillén F. Rapidly progressive dementia in sporadic prion disease: report of unprecedented event in Ecuador and update. Acta Neurol Colomb. 2016; 32(2): 169-78.

10. Jerusa S, Adalberto SN, Christine LM, Fagundes MC, Ribeiro NP, Silva CNH, et al. High phenotypic variability in Gerstmann-Sträussler-Scheinker disease. Arq. Neuro-Psiquiatr. 2017; 75(6): 331-38.

11. Costa AP, Júnior ACSS. Prions: a review of their biochemical properties and the pathological features of the transmissible spongiform en- cephalopathies. Rev. Arq. Científicos. 2018; 1(1): 04-13.

12. Neves AC. O Paradigma do Prion. Rev. Neurociências. 2003; 11(1): 40-45.

13. Cardoso CAO, Navarro MBMA, Soares BEC, Cardoso TAO. Avaliação epidemiológica dos óbitos por doenças priônicas no Brasil sob o enfoque da biossegurança. Cad. Saúde Colet. 2015; 23 (1): 2-10.

14. Okamoto, I. H. Encefalopatia Espongiforme Sub-aguda. Ver. Neurociências. 2004; 12(1): 21-23.

15. Liberski, P. P., Gajos, A., Sikorska, B., \& Lindenbaum, $\mathrm{S}$. Kuru, the first human prion disease. Viruses. 2019; 11(3): 232.

16. Pustiglione $M$, Torres RAT, Eduardo Costa Sá EC. Diseases caused by prions and probable occupational nexus. Rev Bras Med Trab. 2014; 12(2): 96-9.

17. Araújo $A Q C$. Prionic diseases. Arq Neuropsiquiatr. 2013; 71(9-B): 731-37.

18. Roos R, Gajdusek DC, Gibbs CJ Jr. The clinical characteristics of transmissible Creutzfeldt-Jakob disease. Brain. 1973; (96): 1-20.

19. Tyler KL, Martin JB. Infections diseases of the central nervous system. Philadelphia: F.A. Davis. 1993.

20. Arata H, Takashima H, Hirano R, et al. Early clinical signs and imaging findings in Gerstmann-Straussler-Scheinker syndrome. Neurology. 2006; 66(11): 1672-78.

21. Krasnianski A, Bartl M, Sanchez Juan PJ, et al. Fatal familial insomnia: Clinical features and early identification. Ann Neurol. 2008; 63(5): 658-61. 